\title{
Conditional testing of multiple variants associated with bone mineral density in the FLNB gene region suggests that they represent a single association signal
}

Benjamin H Mullin ${ }^{1,2,3^{*}}$, Cyril Mamotte ${ }^{2}$, Richard L Prince ${ }^{1,3}$, Tim D Spector ${ }^{4}$, Frank Dudbridge ${ }^{5}$ and Scott G Wilson ${ }^{1,3,4}$

\begin{abstract}
Background: Low bone mineral density (BMD) is a primary risk factor for osteoporosis and is a highly heritable trait, but appears to be influenced by many genes. Genome-wide linkage studies have highlighted the chromosomal region 3p14-p22 as a quantitative trait locus for BMD (LOD 1.1 - 3.5). The FLNB gene, which is thought to have a role in cytoskeletal actin dynamics, is located within this chromosomal region and presents as a strong candidate for BMD regulation. We have previously identified significant associations between four SNPs in the FLNB gene and BMD in women. We have also previously identified associations between five SNPs located 5' of the transcription start site (TSS) and in intron 1 of the FLNB gene and expression of FLNB mRNA in osteoblasts in vitro. The latter five SNPs were genotyped in this study to test for association with BMD parameters in a family-based population of 769 Caucasian women.
\end{abstract}

Results: Using FBAT, significant associations were seen for femoral neck BMD Z-score with the SNPs rs11720285, rs 11130605 and rs9809315 ( $P=0.004-0.043)$. These three SNPs were also found to be significantly associated with total hip BMD Z-score $(P=0.014-0.026)$. We then combined the genotype data for these three SNPs with the four SNPs we previously identified as associated with BMD and performed a conditional analysis to determine whether they represent multiple independent associations with BMD. The results from this analysis suggested that these variants represent a single association signal.

Conclusions: The SNPs identified in our studies as associated with BMD appear to be part of a single association signal between the FLNB gene and BMD in our data. FLNB is one of several genes located in 3p14-p22 that has been identified as significantly associated with BMD in Caucasian women.

Keywords: Bone mineral density, Filamin B, SNP, Osteoporosis

\section{Background}

Postmenopausal osteoporosis is a systemic bone disease that is characterised by low bone mass and disturbed micro architecture of bone tissue, resulting in decreased bone strength and a corresponding increase in the risk of fracture [1]. Bone mass peaks in early adult life, but declines in postmenopausal women due to a reduction

\footnotetext{
*Correspondence: Benjamin.Mullin@uwa.edu.au

'Department of Endocrinology \& Diabetes, Sir Charles Gairdner Hospital, Nedlands, Western Australia, Australia

${ }^{2}$ School of Biomedical Sciences and CHIRI Biosciences, Curtin University of

Technology, Bentley, Western Australia, Australia

Full list of author information is available at the end of the article
}

in oestrogen production which has direct effects on bone as well as calcium handling by the intestine and renal system [2]. In addition to these effects and environmental factors, there is a strong genetic effect on peak bone mass, bone loss and fracture rates in postmenopausal women [3]. Twin and family studies suggest that $50-85 \%$ of the variance in peak bone mass [4-7] and $25-68 \%$ of the variance in osteoporotic fracture is heritable [8-10].

The whole genome linkage scanning approach has identified multiple quantitative trait loci (QTL) for bone mineral density (BMD) [11], strongly suggesting

\section{Biomed Central}

(c) 2013 Mullin et al.; licensee BioMed Central Ltd. This is an open access article distributed under the terms of the Creative Commons Attribution License (http://creativecommons.org/licenses/by/2.0), which permits unrestricted use, distribution, and reproduction in any medium, provided the original work is properly cited. 
that genetic influence for the phenotype is mediated through multiple genes. The 3p14-p22 region of the human genome has been identified as a QTL for BMD in multiple genome-wide linkage studies (LOD 1.1 - 3.5) [12-15]. The Filamin B (FLNB) gene, which is thought to have a role in cytoskeletal actin dynamics [16], is located within this chromosomal region and presents as a strong candidate for BMD regulation. Mutations within the $F L N B$ gene have been implicated in a variety of genetic disorders characterised by skeletal malformation, some of which include: spondylocarpotarsal synostosis syndrome [17-19], Larsen syndrome [18,20], atelosteogenesis types I and III $[18,21]$ and boomerang dysplasia [22]. Associations have also been identified between polymorphism in $F L N B$ and human stature variation in a genome-wide association study [23].

We have previously identified significant associations between four single nucleotide polymorphisms (SNPs) in the FLNB gene and BMD in Caucasian women [24]. Two of these SNPs were identified as being in moderate to strong linkage disequilibrium (LD) with five other SNPs located either $5^{\prime}$ of the transcription start site (TSS) or in intron 1 of the gene, all five of which were significantly associated with expression of FLNB mRNA in 96 human osteoblast cell lines [24]. Based on this data, we decided to perform a follow up to our previous study [24] and examine these five SNPs in relation to BMD parameters in a family-based population of Caucasian women. Genotype data for any significant variants would then be combined with the genotype data for the four FLNB SNPs previously associated with BMD [24] in a conditional analysis to determine whether multiple loci exist in the FLNB gene that are independently associated with BMD.

\section{Results}

The demographic and morphometric characteristics of the population are detailed in Table 1 . There are a large number of osteoporotic individuals in this population, resulting in a negative mean BMD Z-score observed at

\section{Table 1 Demographics and bone density of the} population studied

\begin{tabular}{lc}
\hline Variable & Population mean \\
\hline Age (years) & $54.2 \pm 12.7(769)$ \\
Weight $(\mathrm{Kg})$ & $62.7 \pm 11.3(699)$ \\
Total hip DXA BMD $\left(\mathrm{mg} / \mathrm{cm}^{2}\right)$ & $801 \pm 136(760)$ \\
Total hip BMD Z-score & $-0.4 \pm 1.0(760)$ \\
Femoral neck DXA BMD $\left(\mathrm{mg} / \mathrm{cm}^{2}\right)$ & $700 \pm 133(749)$ \\
Femoral neck BMD Z-score & $-0.4 \pm 1.1(749)$ \\
Spine L1-L4 DXA BMD $\left(\mathrm{mg} / \mathrm{cm}^{2}\right)$ & $855 \pm 158(767)$ \\
Spine BMD Z-score & $-0.7 \pm 1.3(767)$ \\
\hline
\end{tabular}

Results are given as mean $\pm S D$ (number of measurements). each site studied. All 5 SNPs genotyped were in HardyWeinberg equilibrium as determined using a $X^{2}$ test. LD analysis revealed that none of the 5 SNPs genotyped were in $\mathrm{LD}$ of $\mathrm{r}^{2}>0.8$ with each other (Figure 1). An additional LD analysis revealed that one of the 5 SNPs genotyped in this study, rs839230, is in LD of $\mathrm{r}^{2}>0.8$ with rs704529 which was genotyped in our previous study [24]. However, none of the other 4 SNPs genotyped in this study were in LD of $\mathrm{r}^{2}>0.8$ with any of the other SNPs genotyped in our previous study [24]. The chromosomal position and allele distribution of the 5 SNPs genotyped in this study and the 13 SNPs genotyped in our previous study [24] is detailed in Table 2.

\section{Locus specific analyses: effects of individual SNP genotypes on phenotypic data}

Using FBAT, significant associations were seen for femoral neck BMD Z-score with the SNPs rs11720285, rs11130605 and rs9809315 $(P=0.005,0.043$ and 0.004 respectively). These three SNPs were also found to be significantly associated with total hip BMD Z-score $(P=$ $0.014,0.026$ and 0.022 respectively). No significant associations were observed between any of the 5 SNPs examined and spine BMD Z-score. After correction of the data for testing 5 SNPs across 3 anatomical sites, the significant association between rs9809315 and femoral neck BMD Zscore was maintained $(P=0.028)$. Estimates of the additive genetic effect suggest that the minor alleles at rs11720285 $(C), \operatorname{rs} 11130605(T)$ and rs9809315 (T) are associated with an increased BMD Z-score at both the total hip and femoral neck sites (Table 3).

\section{Haplotype analysis}

A 3-SNP haplotype analysis was carried out using rs11720285, rs11130605 and rs9809315 to determine whether haplotypes of the LD blocks tagged by each SNP would prove to be more significantly associated with femoral neck or total hip BMD Z-score than in the individual SNP analysis. Six haplotypes with a frequency greater than $4 \%$ in the population were identified. Significant associations were observed with femoral neck BMD Z-score only (Table 4), although the level of significance did not surpass that observed in the individual SNP analysis for this phenotype. The CTT haplotype was found to have a strong positive influence on femoral neck BMD Z-score.

\section{Bioinformatics analysis}

The SNP rs11130605 has been identified by the HapMap Genome Browser [25] (release \#27) as being in complete LD with the SNPs rs7631741 and rs7634753 in the CEU population (Utah residents with Northern and Western European ancestry). These two SNPs were therefore included in the bioinformatics analysis. 


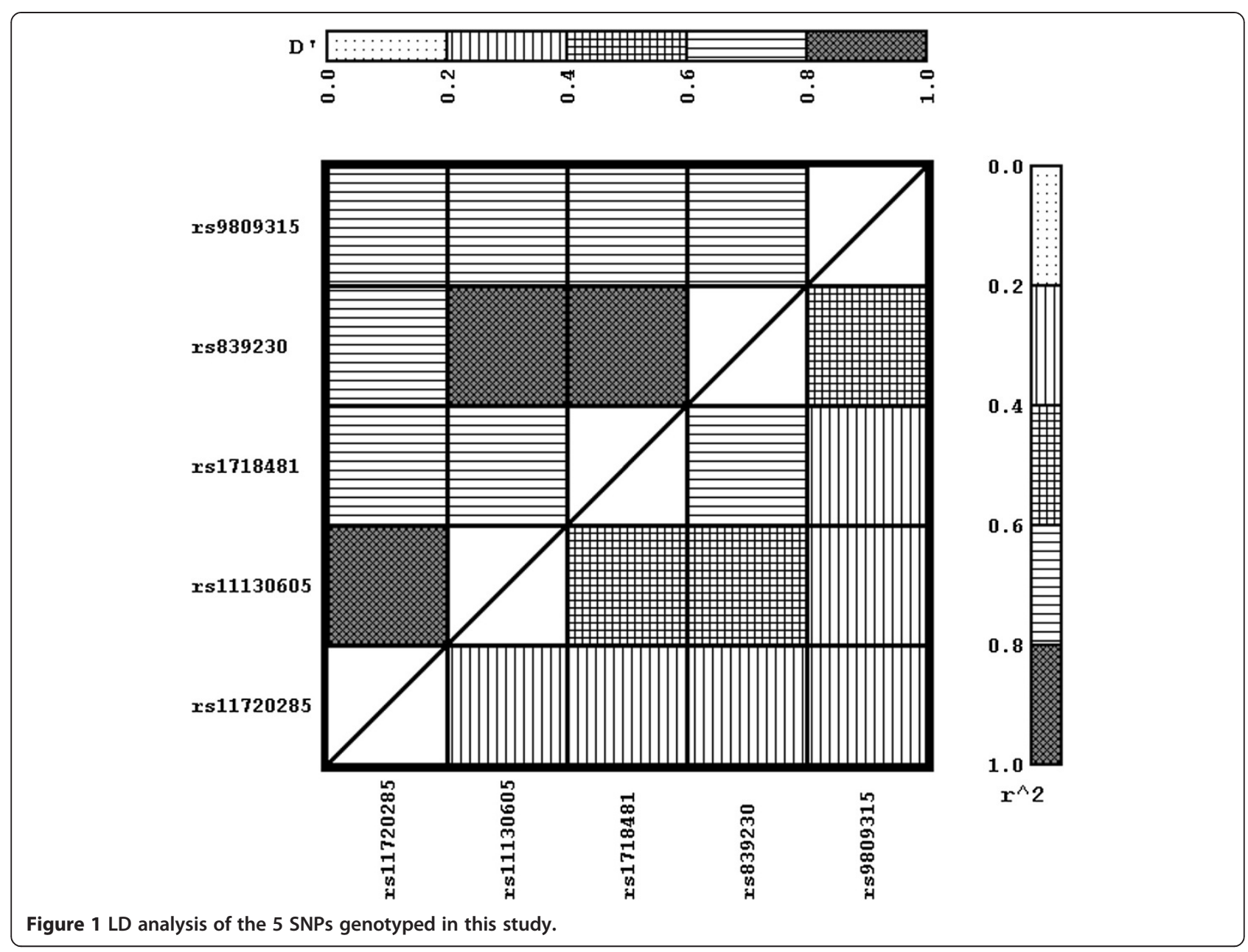

The rs11130605 polymorphism has an F-SNP score of 0.101 as it is located in a potential regulatory region. rs7634753 has an F-SNP score of 0.242 with the more common $C$ allele resulting in the loss of an STRE site and the gain of N-Myc and USF sites. The rs9809315 polymorphism also has an F-SNP score of 0.242 and is located in a potential regulatory region, with the more common $C$ allele resulting in loss of HSF, Dfd, CdxA and GCN4 sites. No functional information currently exists for rs11720285 and rs7631741 in F-SNP, so these variants were analysed using HaploReg [26]. Using this resource, the more common $A$ allele at rs11720285 was found to result in the loss of a Sox_9 site with the gain of Evi-1_2 and Hoxa4 sites. The more common $T$ allele at rs7631741 was found to result in a gain of a HMGIY_2 site.

\section{Conditional analysis}

The genotype data for rs11720285, rs11130605 and rs9809315 was combined with that for the four other SNPs from the FLNB gene that we previously identified as associated with BMD [24] for a conditional analysis.
These four SNPs are rs7637505, rs9822918, rs2177153 and rs2001972. Out of these seven SNPs, rs2177153 demonstrated the strongest associations with BMD and was therefore used as the conditioning marker. Once the data had been conditioned on rs2177153, no significant associations with femoral neck or total hip BMD Z-score were observed for any of the other six SNPs $(P=0.32-0.93)$.

\section{Discussion}

We previously identified 5 SNPs from the $5^{\prime}$ region of the $F L N B$ gene that were strongly associated with expression levels of FLNB mRNA [24], 3 of which have been shown here to be significantly associated with age-adjusted total hip and femoral neck BMD in Caucasian women. The minor allele at each of these 3 SNP sites was associated with an increased BMD Z-score in this study and a reduced level of FLNB mRNA in our previous study [24]. However, when the genotype data for these 3 SNPs was combined with that for 4 FLNB SNPs previously identified as associated with BMD and conditioned on the most significantly associated SNP, 
Table 2 Position and allele distribution of all FLNB variants genotyped in this and our previous study

\begin{tabular}{|c|c|c|c|c|}
\hline SNP & Chromosome position* & Location* & Major/minor allele & Minor allele frequency (\%) \\
\hline rs11720285 & 57961370 & $5^{\prime}$ of TSS & $\mathrm{A} / \mathrm{C}$ & 25.1 \\
\hline rs7637505 ${ }^{\dagger}$ & 57968393 & $5^{\prime}$ of TSS & $\mathrm{A} / \mathrm{T}$ & 29.4 \\
\hline rs6445938 & 57974822 & $5^{\prime}$ of TSS & $A / G$ & 23.1 \\
\hline rs11130605 & 57989169 & $5^{\prime}$ of TSS & $C / T$ & 39.2 \\
\hline rs6798382 ${ }^{\dagger}$ & 57991811 & $5^{\prime}$ of TSS & $\mathrm{G} / \mathrm{A}$ & 28.6 \\
\hline rs4681772 ${ }^{\dagger}$ & 57992512 & $5^{\prime}$ of TSS & $A / G$ & 32.1 \\
\hline rs1658351 ${ }^{\dagger}$ & 58013573 & Intron 1 & $A / G$ & 33.5 \\
\hline rs1718481 & 58025903 & Intron 1 & $\mathrm{G} / \mathrm{A}$ & 42.7 \\
\hline rs $704529^{\dagger}$ & 58036651 & Intron 1 & $A / G$ & 36.2 \\
\hline rs839230 & 58036792 & Intron 1 & $\mathrm{G} / \mathrm{A}$ & 36.2 \\
\hline rs9809315 & 58050265 & Intron 1 & $C / T$ & 30.2 \\
\hline rs9822918 & 58057684 & Intron 1 & $C / A$ & 44.6 \\
\hline rs $2177153^{\dagger}$ & 58092346 & Intron 11 & $A / G$ & 31.8 \\
\hline rs1131356 & 58109162 & Exon 21, Asp > Asn & $\mathrm{G} / \mathrm{A}$ & 22.9 \\
\hline rs12632456 ${ }^{+}$ & 58118555 & Exon 26, Val > Met & $\mathrm{G} / \mathrm{A}$ & 23.2 \\
\hline rs $2001972^{\dagger}$ & 58123249 & Intron 28 & $C / A$ & 37.6 \\
\hline rs4284952 & 58126223 & Intron 29 & C/A & 34.6 \\
\hline rs4234386 & 58150433 & Intron 43 & $\mathrm{G} / \mathrm{A}$ & 24.4 \\
\hline
\end{tabular}

*Relative to GenBank reference sequence NM_001457, Genome Build 37.5.

${ }^{\dagger}$ Variant genotyped in our previous study [24].

none of the associations remained significant. This suggests that these variants represent a single association signal between the FLNB gene and BMD in this study population. This is not the first time that common variation within a gene that has previously been identified as underlying a rare monogenetic form of osteoporosis and/or high bone mass has been implicated in BMD regulation, other examples including the SOST, CLCN7 and LRP5 genes [27].

Although rs2177153 demonstrated the most significant associations with BMD in the study population combined dataset [24], we cannot be sure that this is the quantitative

Table 3 Additive value of minor allele for FLNB variants associated with BMD Z-score in this and our previous study

\begin{tabular}{|c|c|c|c|}
\hline$\underline{\text { SNP }}$ & BMD Z-score phenotype & Additive value of minor allele & $P$ \\
\hline \multirow[t]{2}{*}{ rs11720285 } & Femoral neck & $+0.306(366)$ & 0.03 \\
\hline & Total hip & $+0.274(373)$ & 0.053 \\
\hline \multirow[t]{2}{*}{ rs7637505 } & Femoral neck & $+0.287(422)$ & 0.031 \\
\hline & Total hip & $+0.262(434)$ & 0.033 \\
\hline \multirow[t]{2}{*}{ rs11130605 } & Femoral neck & $+0.241(575)$ & 0.045 \\
\hline & Total hip & $+0.268(592)$ & 0.03 \\
\hline \multirow[t]{2}{*}{ rs9809315 } & Femoral neck & $+0.304(435)$ & 0.014 \\
\hline & Total hip & $+0.254(448)$ & 0.045 \\
\hline \multirow[t]{2}{*}{ rs9822918 } & Femoral neck & $+0.397(650)$ & 0.002 \\
\hline & Total hip & $+0.414(668)$ & 0.002 \\
\hline \multirow[t]{2}{*}{ rs $2177153^{\dagger}$} & Femoral neck & $+0.537(459)$ & 0.0004 \\
\hline & Total hip & $+0.443(474)$ & 0.001 \\
\hline \multirow[t]{2}{*}{ rs2001972 } & Femoral neck & $+0.254(547)$ & 0.043 \\
\hline & Total hip & $+0.264(563)$ & 0.041 \\
\hline
\end{tabular}

Results are given as additive effect on the trait of the minor allele relative to the more common allele (number of alleles included in analysis), derived from UNPHASED v3.1.5.

${ }^{\dagger}$ Variant genotyped in our previous study [24]. 
Table 4 Haplotype analysis and additive value of each haplotype relevant to femoral neck BMD Z-score

\begin{tabular}{|c|c|c|c|c|c|c|c|}
\hline \multirow[t]{2}{*}{ BMD Z-score phenotype } & \multicolumn{7}{|c|}{ Haplotype (rs11720285, rs11130605, rs9809315) } \\
\hline & ACC allele & CTT allele & ATC allele & ACT allele & ATT allele & CTC allele & $P$ \\
\hline Femoral neck & $0(769)$ & $+0.72(260)$ & $+0.184(148)$ & $+0.044(83)$ & $-0.442(82)$ & $-0.164(76)$ & 0.005 \\
\hline
\end{tabular}

trait nucleotide responsible for the associations seen. Of the three SNPs identified in this study as associated with BMD, rs11130605 demonstrated the most significant associations with FLNB mRNA expression levels in our previous study [24]. This could suggest that the SNP rs11130605, or another SNP in very strong LD with it, is the causal variant responsible for the associations seen. It is interesting that F-SNP identified rs11130605 and rs9809315 as being located in potential regulatory regions. These SNPs had F-SNP scores of 0.101 and 0.242 respectively, with the median F-SNP score for a neutral SNP thought to be around 0.176 [28]. The SNP rs7634753 also had an F-SNP score of 0.242 , with the common allele predicted to cause the gain of binding sites for the transcription factors N-Myc and USF. Both of these transcription factors have been shown to have a role in bone, with $\mathrm{N}$-Myc having been implicated in the development of the limb bones in mice $[29,30]$ and USF having been shown to have a role in the process of receptor activator of nuclear factor kappa-B ligand (RANKL) induced tartrate-resistant acid phosphatase (TRAP) transcription during osteoclast differentiation [31]. Variation at rs11720285 was found to alter Hoxa4 and Sox_9 sites. Hoxa4 may have a role in vertebral development in mice [32], while mutations in the human SOX9 gene have been found to cause campomelic dysplasia [33], a disease characterised by shortness and bowing of long tubular bones, hypoplastic scapulae and narrow iliac wings. There are two non-synonymous coding changes within the $F L N B$ gene that have a minor allele frequency $>1 \%$ in Caucasians, both of which were genotyped in our previous study [24] and neither of which demonstrated significant associations with BMD parameters.

A recent study published by $\mathrm{Li}$ et al. [34] analysed seven SNPs from the FLNB gene, including the SNPs rs9822918 and rs2177153 genotyped in our previous study [24], for association with BMD parameters in a case-control population of 1,080 Chinese females, 533 of whom were postmenopausal. The authors were not able to replicate the associations that we observed between rs2177153 and BMD, which is probably due to the fact that this SNP had a minor allele frequency of only 0.02 in their population compared to a mean of 0.32 in our study. However, they did observe significant associations between rs9822918 and BMD at the total hip [34]. Although providing more support of a role for the FLNB gene in osteoporosis, comparisons with this study and our previous study must be done with caution due to differences in study design as well as differences in the ethnicity of the study subjects.

In addition to the evidence suggesting a role for the human FLNB gene in bone development [17-22], there is increasing evidence to suggest that the murine $F \ln b$ gene also has a role in bone. Flnb expression has been detected in vertebral bodies obtained from mouse embryos, and it has been suggested that the gene plays a role in vertebral segmentation, joint formation and endochondral ossification [18]. Zhou et al. [35] generated mice with a targeted disruption of the $F \ln b$ gene and observed impaired development of the microvasculature and skeletal systems in Flnb-deficient embryos, few of which reached term. Those that were born were very small and had severe skeletal malformations including scoliotic and kyphotic spines, fusion of vertebral bodies, lack of intervertebral discs and reduced hyaline matrix in the extremities, thorax and vertebrae [35]. Another study published by Lu et al. [36] found that Flnb-deficient mice presented with shortened distal limbs and small body size, abnormal spinal curvatures, dysmorphic facial/ calvarial bones and develop fusion of the ribs and vetebrae, which appeared to be caused by a delay in chondrocyte development.

Over 70 binding partners have been identified to date for the filamin proteins $[37,38]$. They are thought to have a role in stabilising the actin cytoskeleton, providing a link between the actin network and the cellular membranes, and mediating interactions between actin and transmembrane receptors [16]. Filamins act to maintain the structural integrity of cells by crosslinking the actin cytoskeleton into 3D structures [16,39]. The ability of filamin proteins to bind actin at their $\mathrm{N}$-terminus and form tail-to-tail homodimers at their $\mathrm{C}$-terminus allows them to create the orthogonal actin networks and bundles that result in gelation [40]. It has also been proposed that filamins are important during foetal development, regulating the communication between extracellular signals and the cytoskeleton to guide migration of cells into the correct anatomical sites [16].

FLNB is the third gene from the 3p14-p22 region of the human genome that we have found to be associated with BMD in Caucasian women, the other two being ARHGEF3 [41] and RHOA [42]. Interestingly, all three of these genes appear to have a role in cytoskeletal 
dynamics and actin polymerisation $[16,43,44]$. It is possible that more than one gene from this chromosomal region may be responsible for the linkage observed between 3p14-p22 and BMD. A recently published meta-analysis of 17 genome-wide association studies identified 56 loci associated with BMD, including the CTNNB1 gene located in 3p22.1, and 14 loci associated with risk of fracture at the genome-wide significance level [27]. Although providing some weak evidence of association for SNPs in FLNB with BMD, the SNPs analysed here were not identified in this meta-analysis as associated with BMD at the genome-wide significance level $(P<5 \times$ $\left.10^{-8}\right)$. The results of the meta-analysis must be treated with caution though as allele risk modelling suggested that only $5.8 \%$ of the total genetic variance in femoral neck BMD was accounted for by the genome-widesignificant SNPs reported in the study [27]. The role of rare or private variants, functional SNPs or small insertions and deletions that are not well represented by the genome-wide association study SNP arrays due to weak $\mathrm{LD}$, may explain the inability of the meta-analysis to characterise most of the source of the genetic variance.

\section{Conclusions}

Polymorphism at rs11720285, rs11130605 and rs9809315, all of which are located either $5^{\prime}$ of the TSS or in intron 1 of the $F L N B$ gene and have been previously reported to be associated with FLNB mRNA expression in osteoblasts in vitro [24], has been identified as significantly associated with BMD in Caucasian women in this study. The fact that these SNPs are located in non-coding regions of the gene and influence mRNA levels indicates that the associations observed are due to regulatory effects on the gene. A conditional analysis of the genotype data for these SNPs combined with those showing associations with BMD from our previous study [24] suggests a single association signal between these variants and BMD.

\section{Methods}

\section{Subjects}

A total of 769 women from 335 families were recruited in Australia and the UK. This family-based population included siblings recruited in 1998 for a study of the genetics of osteoporosis [13] and is the same as the family-based cohort used in our previous FLNB study [24] with the inclusion of one additional sibling pair. Exclusion criteria were applied where possible and included the presence of bone cancer, hyperparathyroidism, unstable thyroid disease, long term steroid use (> $5 \mathrm{mg} /$ day for more than 6 months and presently on therapy), chronic immobility, rheumatoid arthritis, anorexia nervosa, osteomalacia, amenorrhea for $>6$ months, premature cessation of regular menstruation or surgical oophorectomy +/HRT (age < 40 yrs), and epilepsy with use of anticonvulsant medication for $>1$ year. All subjects from the study provided written informed consent and the experimental protocols were approved by the Sir Charles Gairdner Group Human Research Ethics Committee and the St Thomas' Hospital Research Ethics Committee.

At a clinic visit data including age, height, weight, medical, gynaecological, and lifestyle data were recorded and a blood sample collected. Dual energy X-ray absorptiometry (DXA) BMD was assessed (Hologic Inc., Bedford, MA, USA) at the lumbar spine L1-L4 and the total hip that includes an area from the femoral neck to just below the lesser trochanter. Within this area the femoral neck sub-region is widely used in clinical practice for prediction of fracture propensity and was therefore also included in the study. Due to the range of ages in this cohort, BMD data was adjusted for age prior to analysis by conversion to BMD Z-scores.

\section{Genotyping}

Genomic DNA was extracted and purified from EDTA whole blood obtained from each subject [45]. Genotyping was performed on genomic DNA using the TaqMan assay, which utilises fluorogenic 5 ' nuclease chemistry, in 384-well PCR plate format. Using this technique the genotype call rate was $99.3 \%$ and the estimated error rate was $<0.1 \%$.

\section{SNP selection}

5 SNPs located either $5^{\prime}$ of the TSS or in intron 1 of the FLNB gene were selected for genotyping. These were selected based on previously published data suggesting that all five SNPs are significantly associated with expression of FLNB mRNA in 96 human osteoblast cell cultures [24].

\section{Statistical analysis}

Data from the cohort was analysed using the FBAT (Family Based Association Tests) software to test for association within sib-pairs, a method based on the allelic transmission disequilibrium test [46]. We used a within-family additive genetic association model and the empirical variance estimator was used to allow for prior linkage to the region. Correction for multiple testing was performed by randomly permuting phenotypes within sibships and repeating all FBAT tests on the permuted datasets. The minimum P-values were recorded for 10,000 random reassignments of the data using an automated script written in Perl. This approach was used to correct for tests of multiple SNPs within each phenotype, and also for tests of multiple SNPs across multiple phenotypes.

UNPHASED v3.1.5 was used to estimate the genetic effect size in this cohort by generating an additive value as an estimate to how each allele influences the trait value relative to the most common allele [47]. This 
program was also used to perform a haplotype analysis and a conditional analysis. Throughout, two-tailed Pvalues are reported, with $P<0.05$ considered significant. LD between the different SNPs was evaluated using the JLIN software [48].

\section{Bioinformatics analysis}

An in silico analysis of SNP targets was performed using the Functional Single Nucleotide Polymorphism (F-SNP) database [49], which integrates data from 16 bioinformatics resources to help identify SNPs that may disrupt functional genomics regions. Any variants not present in the F-SNP database were analysed using HaploReg [26], a web-based tool for exploring annotations of the non-coding genome.

\section{Competing interests}

The authors declare they have no competing interests.

\section{Authors' contributions}

$\mathrm{BHM}$ performed the genotyping, statistical analysis and drafted the manuscript. CM and RLP participated in the design and co-ordination of the study. TDS and SGW were involved in the recruitment of the study subjects and participated in study design and co-ordination. FD assisted in the statistical analysis of the data and study design. All authors read and approved the final manuscript.

\section{Acknowledgements}

This study was supported by Arthritis Australia, Grant 0402067 and Curtin University Postgraduate Scholarships.

\section{Author details \\ 'Department of Endocrinology \& Diabetes, Sir Charles Gairdner Hospital, Nedlands, Western Australia, Australia. ${ }^{2}$ School of Biomedical Sciences and CHIRI Biosciences, Curtin University of Technology, Bentley, Western Australia, Australia. ${ }^{3}$ School of Medicine and Pharmacology, University of Western Australia, Nedlands, Western Australia, Australia. ${ }^{4}$ Twin \& Genetic Epidemiology Research Unit, St Thomas' Hospital Campus, King's College London, London, UK. ${ }^{5}$ Faculty of Epidemiology and Population Health, London School of Hygiene and Tropical Medicine, London, UK.}

Received: 19 July 2013 Accepted: 30 October 2013

Published: 31 October 2013

\section{References}

1. Kanis JA, Melton LJ 3rd, Christiansen C, Johnston CC, Khaltaev N: The diagnosis of osteoporosis. J Bone Miner Res 1994, 9:1137-1141.

2. Dick IM, Devine A, Beilby J, Prince RL: Effects of endogenous estrogen on renal calcium and phosphate handling in elderly women. Am J Physiol Endocrinol Metab 2005, 288:E430-E435.

3. Ralston SH, Uitterlinden AG: Genetics of osteoporosis. Endocr Rev 2010, 31:629-662.

4. Gueguen R, Jouanny P, Guillemin F, Kuntz C, Pourel J, Siest G: Segregation analysis and variance components analysis of bone mineral density in healthy families. J Bone Miner Res 1995, 10:2017-2022.

5. Krall EA, Dawson-Hughes B: Heritable and life-style determinants of bone mineral density. J Bone Miner Res 1993, 8:1-9.

6. Slemenda CW, Turner CH, Peacock M, Christian JC, Sorbel J, Hui SL, Johnston CC: The genetics of proximal femur geometry, distribution of bone mass and bone mineral density. Osteoporos Int 1996, 6:178-182.

7. Smith DM, Nance WE, Kang KW, Christian JC, Johnston CC Jr: Genetic factors in determining bone mass. J Clin Invest 1973, 52:2800-2808.

8. Andrew T, Antioniades L, Scurrah KJ, Macgregor AJ, Spector TD: Risk of wrist fracture in women is heritable and is influenced by genes that are largely independent of those influencing BMD. J Bone Miner Res 2005, 20:67-74.

9. Deng HW, Chen WM, Recker S, Stegman MR, Li JL, Davies KM, Zhou Y, Deng H, Heaney R, Recker RR: Genetic determination of Colles' fracture and differential bone mass in women with and without Colles' fracture. J Bone Miner Res 2000, 15:1243-1252.

10. Michaelsson K, Melhus H, Ferm H, Ahlbom A, Pedersen NL: Genetic liability to fractures in the elderly. Arch Intern Med 2005, 165:1825-1830.

11. Xu XH, Dong SS, Guo Y, Yang TL, Lei SF, Papasian CJ, Zhao M, Deng HW: Molecular genetic studies of gene identification for osteoporosis: the 2009 update. Endocr Rev 2010, 31:447-505.

12. Duncan EL, Brown MA, Sinsheimer J, Bell J, Carr AJ, Wordsworth BP, Wass JA: Suggestive linkage of the parathyroid receptor type 1 to osteoporosis. J Bone Miner Res 1999, 14:1993-1999.

13. Wilson SG, Reed PW, Bansal A, Chiano M, Lindersson M, Langdown M, Prince RL, Thompson D, Thompson E, Bailey M, Kleyn PW, Sambrook P, Shi MM, Spector TD: Comparison of genome screens for two independent cohorts provides replication of suggestive linkage of bone mineral density to 3p21 and 1p36. Am J Hum Genet 2003, 72:144-155.

14. Wynne F, Drummond FJ, Daly M, Brown M, Shanahan F, Molloy MG, Quane KA: Suggestive linkage of 2p22-25 and 11q12-13 with low bone mineral density at the lumbar spine in the Irish population. Calcif Tissue Int 2003, 72:651-658.

15. Xiao P, Shen H, Guo YF, Xiong DH, Liu YZ, Liu YJ, Zhao L, Long JR, Guo Y, Recker RR, Deng HW: Genomic regions identified for BMD in a large sample including epistatic interactions and gender-specific effects. J Bone Miner Res 2006, 21:1536-1544.

16. Stossel TP, Condeelis J, Cooley L, Hartwig JH, Noegel A, Schleicher M, Shapiro SS: Filamins as integrators of cell mechanics and signalling. Nat Rev Mol Cell Biol 2001, 2:138-145.

17. Brunetti-Pierri N, Esposito V, de Brasi D, Mattiacci DM, Krakow D, Lee B, Salerno M: Spondylocarpotarsal synostosis: long-term follow-up of a case due to FLNB mutations. Am J Med Genet A 2008, 146A:1230-1233.

18. Krakow D, Robertson SP, King LM, Morgan T, Sebald ET, Bertolotto C, Wachsmann-Hogiu S, Acuna D, Shapiro SS, Takafuta T, Aftimos S, Kim CA, Firth H, Steiner CE, Cormier-Daire V, Superti-Furga A, Bonafe L, Graham JM Jr, Grix A, Bacino CA, Allanson J, Bialer MG, Lachman RS, Rimoin DL, Cohn $\mathrm{DH}$ : Mutations in the gene encoding filamin B disrupt vertebral segmentation, joint formation and skeletogenesis. Nat Genet 2004, 36:405-410

19. Mitter D, Krakow D, Farrington-Rock C, Meinecke P: Expanded clinical spectrum of spondylocarpotarsal synostosis syndrome and possible manifestation in a heterozygous father. Am J Med Genet A 2008, 146A:779-783.

20. Bicknell LS, Farrington-Rock C, Shafeghati Y, Rump P, Alanay Y, Alembik Y, Al-Madani N, Firth H, Karimi-Nejad MH, Kim CA, Leask K, Maisenbacher M, Moran E, Pappas JG, Prontera P, de Ravel T, Fryns JP, Sweeney E, Fryer A, Unger S, Wilson LC, Lachman RS, Rimoin DL, Cohn DH, Krakow D, Robertson SP: A molecular and clinical study of Larsen syndrome caused by mutations in FLNB. J Med Genet 2007, 44:89-98.

21. Farrington-Rock C, Firestein MH, Bicknell LS, Superti-Furga A, Bacino CA, Cormier-Daire V, Le Merrer M, Baumann C, Roume J, Rump P, Verheij JB, Sweeney E, Rimoin DL, Lachman RS, Robertson SP, Cohn DH, Krakow D: Mutations in two regions of FLNB result in atelosteogenesis I and III. Hum Mutat 2006, 27:705-710.

22. Bicknell LS, Morgan T, Bonafe L, Wessels MW, Bialer MG, Willems PJ, Cohn DH, Krakow D, Robertson SP: Mutations in FLNB cause boomerang dysplasia. J Med Genet 2005, 42:e43.

23. Lei SF, Tan LJ, Liu XG, Wang L, Yan H, Guo YF, Liu YZ, Xiong DH, Li J, Yang TL, Chen XD, Guo Y, Deng FY, Zhang YP, Zhu XZ, Levy S, Papasian CJ, Hamilton JJ, Recker RR, Deng HW: Genome-wide association study identifies two novel loci containing FLNB and SBF2 genes underlying stature variation. Hum Mol Genet 2009, 18:1661-1669.

24. Wilson SG, Jones MR, Mullin BH, Dick IM, Richards JB, Pastinen TM, Grundberg E, Ljunggren O, Surdulescu GL, Dudbridge F, Elliott KS, Cervino AC, Spector TD, Prince RL: Common sequence variation in FLNB regulates bone structure in women in the general population and FLNB mRNA expression in osteoblasts in vitro. J Bone Miner Res 2009, 24:1989-1997.

25. International HapMap Consortium: The International HapMap Project. Nature 2003, 426:789-796.

26. Ward LD, Kellis M: HaploReg: a resource for exploring chromatin states, conservation, and regulatory motif alterations within sets of genetically linked variants. Nucleic Acids Res 2012, 40:D930-D934.

27. Estrada K, Styrkarsdottir U, Evangelou E, Hsu YH, Duncan EL, Ntzani EE, Oei L, Albagha OM, Amin N, Kemp JP, Koller DL, Li G, Liu CT, Minster RL, Moayyeri A, Vandenput L, Willner D, Xiao SM, Yerges-Armstrong LM, Zheng HF, Alonso N, Eriksson J, Kammerer CM, Kaptoge SK, Leo PJ, Thorleifsson G, 
Wilson SG, Wilson JF, Aalto V, Alen M: Genome-wide meta-analysis identifies 56 bone mineral density loci and reveals 14 loci associated with risk of fracture. Nat Genet 2012, 44:491-501.

28. Lee PH, Shatkay H: An integrative scoring system for ranking SNPs by their potential deleterious effects. Bioinformatics 2009, 25:1048-1055.

29. Ota S, Zhou ZQ, Keene DR, Knoepfler P, Hurlin PJ: Activities of N-Myc in the developing limb link control of skeletal size with digit separation. Development 2007, 134:1583-1592.

30. Zhou ZQ, Shung CY, Ota S, Akiyama H, Keene DR, Hurlin PJ: Sequential and coordinated actions of c-Myc and N-Myc control appendicular skeletal development. PLoS One 2011, 6:e18795.

31. Liu Y, Shi Z, Silveira A, Liu J, Sawadogo M, Yang H, Feng X: Involvement of upstream stimulatory factors 1 and 2 in RANKL-induced transcription of tartrate-resistant acid phosphatase gene during osteoclast differentiation. J Biol Chem 2003, 278:20603-20611.

32. Horan GS, Wu K, Wolgemuth DJ, Behringer RR: Homeotic transformation of cervical vertebrae in Hoxa-4 mutant mice. Proc Natl Acad Sci USA 1994, 91:12644-12648

33. Foster JW, Dominguez-Steglich MA, Guioli S, Kwok C, Weller PA, Stevanovic M, Weissenbach J, Mansour S, Young ID, Goodfellow PN, et al: Campomelic dysplasia and autosomal sex reversal caused by mutations in an SRY-related gene. Nature 1994, 372:525-530.

34. Li GH, Kung AW, Huang QY: Common variants in FLNB/CRTAP, not ARHGEF3 at $3 p$, are associated with osteoporosis in southern Chinese women. Osteoporos Int 2010, 21:1009-1020.

35. Zhou X, Tian F, Sandzen J, Cao R, Flaberg E, Szekely L, Cao Y, Ohlsson C, Bergo MO, Boren J, Akyurek LM: Filamin B deficiency in mice results in skeletal malformations and impaired microvascular development. Proc Natl Acad Sci U S A 2007, 104:3919-3924.

36. Lu J, Lian G, Lenkinski R, de Grand A, Vaid RR, Bryce T, Stasenko M, Boskey A, Walsh C, Sheen V: Filamin B mutations cause chondrocyte defects in skeletal development. Hum Mol Genet 2007, 16:1661-1675.

37. Popowicz GM, Schleicher M, Noegel AA, Holak TA: Filamins: promiscuous organizers of the cytoskeleton. Trends Biochem Sci 2006, 31:411-419.

38. Sarkisian MR, Bartley CM, Rakic P: Trouble making the first move: interpreting arrested neuronal migration in the cerebral cortex. Trends Neurosci 2008, 31:54-61.

39. Stossel TP: From signal to pseudopod. How cells control cytoplasmic actin assembly. J Biol Chem 1989, 264:18261-18264.

40. Gorlin JB, Yamin R, Egan S, Stewart M, Stossel TP, Kwiatkowski DJ, Hartwig $\mathrm{JH}$ : Human endothelial actin-binding protein (ABP-280, nonmuscle filamin): a molecular leaf spring. J Cell Biol 1990, 111:1089-1105.

41. Mullin BH, Prince RL, Dick IM, Hart DJ, Spector TD, Dudbridge F, Wilson SG Identification of a role for the ARHGEF3 gene in postmenopausal osteoporosis. Am J Hum Genet 2008, 82:1262-1269.

42. Mullin BH, Prince RL, Mamotte C, Spector TD, Hart DJ, Dudbridge F, Wilson SG: Further genetic evidence suggesting a role for the RhoGTPase-RhoGEF pathway in osteoporosis. Bone 2009, 45:387-391.

43. Arthur WT, Ellerbroek SM, Der CJ, Burridge K, Wennerberg K: XPLN, a guanine nucleotide exchange factor for RhoA and RhoB, but not RhoC. J Biol Chem 2002, 277:42964-42972.

44. Etienne-Manneville S, Hall A: Rho GTPases in cell biology. Nature 2002, 420:629-635.

45. Johns MB Jr, Paulus-Thomas JE: Purification of human genomic DNA from whole blood using sodium perchlorate in place of phenol. Anal Biochem $1989,180: 276-278$

46. Laird NM, Horvath $S, X u X$ : Implementing a unified approach to familybased tests of association. Genet Epidemiol 2000, 19(Suppl 1):S36-S42.

47. Dudbridge F: Pedigree disequilibrium tests for multilocus haplotypes Genet Epidemiol 2003, 25:115-121.

48. Carter KW, MCCaskie PA, Palmer LJ: JLIN: a java based linkage disequilibrium plotter. BMC bioinformatics 2006, 7:60

49. Lee PH, Shatkay H: F-SNP: computationally predicted functional SNPs for disease association studies. Nucleic Acids Res 2008, 36:D820-D824.

doi:10.1186/1471-2156-14-107

Cite this article as: Mullin et al: Conditional testing of multiple variants associated with bone mineral density in the FLNB gene region suggests that they represent a single association signal. BMC Genetics 2013 14:107.

\section{Submit your next manuscript to BioMed Central and take full advantage of:}

- Convenient online submission

- Thorough peer review

- No space constraints or color figure charges

- Immediate publication on acceptance

- Inclusion in PubMed, CAS, Scopus and Google Scholar

- Research which is freely available for redistribution 